\title{
Epidemiology of traumatic brain injury in Brazil
}

\author{
Raimundo Nonato Ribeiro Fernandes ${ }^{1}$, Marlene Silva ${ }^{2}$ \\ Instituto Cardio Pulmonar, Hospital Português and Universidade Federal da Bahia (UFBA), Salvador, BA, Brazil.
}

\begin{abstract}
Objective: To describe the estimates of morbidity and nosocomial mortality for traumatic brain injury (TBI), along with its causes. Methods: This is a descriptive series of hospitalizations in public Brazilian hospitals, with patients with age among 14 and 69 years, during the period of 2001 to 2007. It was selected the total number of hospitalizations for TBI and others diagnoses. It was estimated prevalence rates, and the coefficients of nosocomial mortality and lethality of TBI and the external causes of TBI for each year of jurisdiction. Results: The hospitalizations for TBI concentrated among men (81.50\%) aged between 14-34 years (53.00\%). The median time of inpatient care was three days, with a total of 52,087 deaths. Falls (35.00\%), and traffic accidents (31.00\%) were the causes that most contributed to TBI. After exclusion of non-specified lesions, the most frequent diagnoses were the diffuse lesions (36.3\%). The prevalence rate and nosocomial lethality remained elevated. Conclusion: It is necessary to establish preventive measures for TBI. The estimates of morbidity and lethality remain high.
\end{abstract}

\section{KEYWORDS}

Craniocerebral trauma, hospitalization, morbidity, mortality, hospital mortality.

\section{RESUMO}

Epidemiologia do traumatismo cranioencefálico no Brasil

Objetivo: Descrever estimativas de morbimortalidade hospitalar por traumatismo cranioencefálico (TCE) e suas circunstâncias no Sistema Único de Saúde (SUS). Métodos: Trata-se de estudo descritivo das internações no Brasil, nos anos de 2001 a 2007, registradas no SUS (14 a 69 anos de idade). Selecionouse o total das internações por TCE e por alguns agravos selecionados. Foram estimados os coeficientes de prevalência, mortalidade e letalidade hospitalar e as causas externas responsáveis pelas internações por TCE. Resultados: As hospitalizações por TCE concentraram-se entre os homens (81,50\%) e nos mais jovens $(53,00 \%)$. Tiveram permanência hospitalar de até três dias $(49,00 \%)$ e ocasionaram 52.087 óbitos. As quedas (35,00\%) e os acidentes de trânsito (31,00\%) foram as circunstâncias que mais contribuíram para o TCE. Excetuando-se as lesões não identificadas, as lesões difusas foram os diagnósticos mais frequentes $(36,3 \%)$. Os coeficientes de prevalência, mortalidade e letalidade hospitalar por TCE não apresentaram diminuição durante o período do estudo. Conclusão: É necessário direcionar esforços das políticas públicas para prevenção do TCE.

\section{PALAVRAS-CHAVE}

Traumatismos craniocerebrais, hospitalização, morbidade, mortalidade, mortalidade hospitalar.

1 Master of Public Health, neurosurgeon, Instituto Cardio Pulmonar and Hospital Português, Salvador, BA, Brazil.

$2 \mathrm{PhD}$ in Public Health, professor and research associate, Integrated Program of Environmental and Occupational Health, Public Health Institute, Universidade Federal da Bahia (UFBA), Salvador, BA, Brazil. 


\section{Introduction}

In general, traumas are common events in every population, and the skull region is one of the most affected locations, what frequently results in severe lesions, with the need of hospitalization most of the times.

It is estimated that the incidence of traumatic brain injury (TBI) worldwide is around 106 cases per 100.000 inhabitants. However, in Latin America and Sub-Saharan Africa, the estimative is upraised, with coefficients around 150 to 170 cases per 100,000 inhabitants. ${ }^{1}$ In Europe, among trauma cases of the 28 topographic regions, the cephalic segment was the third location most affected, with a proportion of 120 cases per 100,000 inhabitants, according to a research that included 10 trauma centers. ${ }^{2}$ On the United States ${ }^{3}$ it was estimated a coefficient of hospitalization due to TBI of 94 cases per 100,000 inhabitants; on the United Kingdom ${ }^{4}$ this number was 229. On Brazil, this coefficient was lower 36 cases per 100,000 inhabitants. $^{5}$

Beyond the magnitude of occurrences and hospitalizations, the TBI is one of the most common causes of death on the United States ${ }^{6}$ being responsible for approximately 50,000 deaths per year, and in many European countries the mortality rates are considerably high. ${ }^{7}$ Nevertheless, the relevance of TBI resides on the fact that the majority of such events cause a social impact, once the patients are put away from their families and daily activities.

Some social strata are more vulnerable to TBI, for being more exposed to the circumstances of violence or accidents. Brazilian ${ }^{5,8}$ and international ${ }^{3,9,10}$ studies have demonstrated that men and young people are frequently more affected by TBI. Many studies describe those circumstances, although the ones that were based on populational data ${ }^{3,5,11}$ have defined the falls as the main circumstance for TBI, while the ones that used data collected from trauma centers have described the traffic accidents as the main cause of this pathology, both in Brazil ${ }^{8,12}$ and in other countries. ${ }^{9,10}$ However, the studies that have focused only on the number of cases attended at emergency rooms or the hospitalizations do not trustworthily represent the factors associated to occurrence or severity of TBI, because such researches do not contemplate the majority of the skull trauma centers, but only some reference centers.

Hence, TBI is a frequent and severe event, which is responsible for high rates of hospitalization and death. In this context, it is also stressed its economic impact, both in Health System and Social Security, and also its social impact due to the disabling sequelae, what makes this subject a relevant issue for Public Health. Nevertheless, there were not found any national researches that highlighted the epidemiological aspects of TBI in Brazilian population. Therefore, this study aims to describe the socio-demographic characteristics of the hospitalizations due to TBI, along with the inpatient mortality rates and all the circumstances that have led to TBI in Brazil, during the period 2001 to 2007.

\section{Methods}

This is a cross-sectional descriptive study of temporal series that targets the residents from Brazil in age from 14 to 69 years, in the period of 2001 to 2007 . The cases included in this research were from patients admitted to public hospitals from the National Health System at least once, during the period from 01/01/2001 to $31 / 12 / 2007$.

It was used populational data from the 2000 Brazilian census, as well as estimatives and projections of inhabitant populational intercensal of the country for each year of the study, considering gender, age, and region. These data were obtained on records that are available electronically on the website of the Brazilian Institute of Geography and Statistics. ${ }^{13}$

The cases of interest were identified using administrative data from secondary sources, at the Hospital Information System of the National Institute of Health (HIS-NIS), which processes and provides these data to the Department of Technology of the National Institute of Health. The files were accessed on the website of DATASUS. ${ }^{14}$ It were selected only the pathologies of interest along with the defined variables for descriptive analysis. After selection, the data were organized in one database and then transferred to the software Statistical Analysis System (SAS 9.1).

The main event of interest was the Traumatic Brain Injury (TBI), defined by the International Classification of Diseases (ICD $10^{\text {th }}$ review) as: S02, S02.0, S02.1, S06-S06.9, S07. For comparison, we have selected five other groups of diseases, which included: Neoplasias of the Respiratory System (NRS): C33, C34-C34.9, Diabetes Mellitus (DM): E10-E14.9, Cerebrovascular Diseases (CVD) - I60-I60.9; I61-I61.9; I63-I63.9; I64; I65-I65.9; I66-I66.9; I67-I67.9. Chronic Lower Respiratory Diseases (CLRD): J41-J41.8; J42; J43-J43.9; J45-J45.9; J46, and all other types of injuries secondary to External Causes (EC): cervical - S12-S19.9; thoracic - S20-S29.9; abdominal, dorsal, lumbar, and pelvic S30-S39.9; shoulder and arm - S40-S49.9; elbow and forearm - S50-S59.9; wrist and hand - S60-S69.9; hip and thigh - S70-S79.9; knee and leg - S80-S89.9; ankle and foot - S90-S99.9, and also polytrauma - T00-T07.

The defined variables for descriptive analysis were the ones that characterized the patients, like gender, considering the biological definition (male and fe- 
male), age (in years) divided in age groups (14-34, 35-54, and 55-69). The variables for characterizing the hospitalization, like the time of inpatient care (in days), were considered in groups (0-3, 4-6, and more than 6). The occurrence of death was registered considering the cause of patient discharge (if death or no death). Another variable included in this study was the specific diagnosis based on ICD-10, taking into account the specificities of TBI defined as: Fractures: S02; S02.0; S02.1; S02.9; Diffuse lesions: S06.0-S06.2; Focal lesions: S06.3; Extradural hematoma: S06.4; Subdural hematoma: S06.5; Subarachnoid hemorrhage: S06.6; Non-specified lesions: S06; S06.7-S06.9.It is also included the variable "circumstance" only for cases of TBI, using the secondary diagnosis (ICD $10^{\text {th }}$ review), which is registered in SIH-SUS database for every case of trauma. This variable was categorized in: Aggressions: W50-W50.9; X72-X74.9; X93-X95.9; X99-X99.9; Y00Y00.9; Y01-Y01.9; Y04-Y04.9; Y07-Y079; Y08; Y09; Y35; Y35.0; Y35.3; Y35.4; Y35.6. Traffic Accident: V01V19.9; V20-V20.9; V30-V87.9; V98; V99. Motorcycle Accident: V20-V29.9. Falls: W00-W19.9. Others: all of the other ICDs of trauma, along with the lost, and the unrated or not codified ones.

\section{Analysis plan}

It were estimated the absolute and relative frequencies for the categories of descriptor variables of the study in total hospitalizations from 2001 to 2007 for TBI and the other selected pathologies (External Causes, Neoplasias of the Respiratory System, Diabetes Mellitus, Cerebrovascular Diseases, and Chronic Lower Respiratory Diseases).

It were calculated the proportions of each circumstance defined in the study among the total number of hospitalizations for TBI each year, followed by a comparison the rations between the periods. For the calculation, it was taken in the numerator the number of hospitalizations for TBI in every circumstance, and in the denominator the total number of hospitalization for TBI in the year. Specifically, for motorcycle accidents, the denominator was the total number of hospitalizations for TBI caused by traffic accidents only.

To investigate the occurrence and distribution of TBI and the other selected pathologies on temporal series, it were estimated the Prevalence Rates of Hospitalization (PRH), the Mortality Rates of Hospitalization (MRH), and the Lethality Rates of Hospitalization (LRH) for TBI and each of other diseases of interest for each year of jurisdiction. For calculating PRH and MRH, it were used in the denominator the estimates of inhabitant populational intercensal and, specifically for LRH, the total amount of inpatient care for each pathology.
The numerator of each coefficient was related to the number of hospitalizations for each disease group of the study and, for LRH, the total amount of deaths due to the disease.

To investigate whether there were differences between years, both in the proportions of the circumstances and the coefficients, it was used a simple linear regression model. It were considered as dependent variables the circumstances and coefficients (PRH, $\mathrm{MRH}$, and LRH), and as independent variables the years of jurisdiction of inpatient care. Results with $\mathrm{p}$ value $\leq 0.05$ were considered statistically significant.

\section{Results}

When describing the characteristics of the hospitalized population from TBI, it was found that male gender was predominant (81.5\%). The age distribution with a peak of $53.0 \%$ of patients on the group of $14-34$ years. The most frequent diagnoses were the diffuse lesions (36.3\%). The total period of inpatient care of $49.0 \%$ of patients with TBI was up to 3 days. It was found that the number of deaths was 52,087 (Table 1).

\begin{tabular}{|c|c|c|}
\hline \multicolumn{3}{|c|}{$\begin{array}{c}\text { Table } 1 \text { - Demographics of traumatic brain injury } \\
\text { hospital admissions, Brazil: } 2001-2007\end{array}$} \\
\hline Variable & $\mathbf{N}$ & $\%$ of total \\
\hline \multicolumn{3}{|l|}{ Gender } \\
\hline Male & 358,780 & 81.5 \\
\hline Female & 81,706 & 18.5 \\
\hline \multicolumn{3}{|l|}{ Age (years) } \\
\hline $14-34$ & 231,827 & 53.0 \\
\hline $35-54$ & 149,898 & 34.0 \\
\hline $55-69$ & 55,675 & 13.0 \\
\hline \multicolumn{3}{|l|}{ Diagnostics } \\
\hline Fractures & 11,125 & 2.5 \\
\hline Extradural hematoma & 20,923 & 4.8 \\
\hline Subdural hematoma & 27,447 & 6.3 \\
\hline Focal lesions & 31,644 & 7.2 \\
\hline Diffuse lesions & 159,241 & 36.3 \\
\hline Subarachnoid hemorrhage & 1,856 & 0.4 \\
\hline Non-specified lesions & 186,742 & 42.5 \\
\hline \multicolumn{3}{|l|}{ Time of inpatient care (in days) } \\
\hline $0-3$ & 216,210 & 49.0 \\
\hline $4-6$ & 101,118 & 23.0 \\
\hline$>6$ & 123,158 & 28.0 \\
\hline \multicolumn{3}{|l|}{ Deaths } \\
\hline Yes & 52,087 & 12.0 \\
\hline No & 388,399 & 88.0 \\
\hline
\end{tabular}


Figure 1 reveals that among the analyzed circumstances that led to the hospitalizations due to TBI during the entire period, the falls were the most prevalent (35.0\%), followed by traffic accidents $(31.0 \%)$, and aggressions $(8.0 \%)$, which remained stable both in magnitude and in order. When analyzing only the traffic accidents, it is possible to identify that the motorcycle accident was the leading circumstance for TBI with the greatest increase in occurrence, which in 2001 accounted for 2,749 admissions and in 2007, for 7,574 admissions, representing approximately $35.0 \%$ of all TBI cases secondary to traffic accidents, with a statistically significant increase ( $\mathrm{p}$ value $=0.0001)$.

Although TBI has been responsible for 440,000 hospitalizations in the entire period of study, it was ranked fifth in the magnitude of the distribution of the $\mathrm{PRH}$ (Figure 2). EC presented the major PRH values,

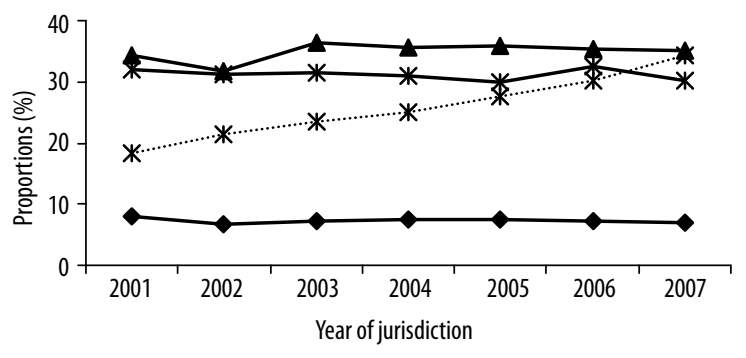

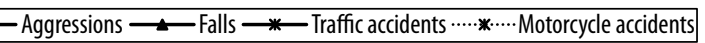

Figure 1 - Distribution of the hospitalizations for traumatic brain injury on the public health system, according to the circumstance and year of jurisdiction. (Brazil: 2001-2007)

Traffic accidents: all of the traffic accidents, also the ones involving motorcycles. Motorcycle accidents: the accidents involving exclusively motorcycles. To calculate the proportion, the denominator was all hospitalizations for TBI due to traffic accidents.

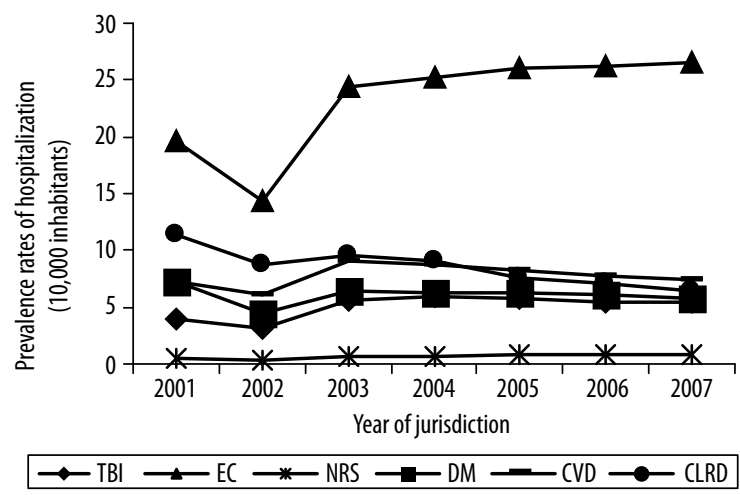

Figure 2 - Prevalence rates of hospitalization on the public health system, for traumatic brain injury and the other selected pathologies, according to the year of jurisdiction. (Brazil: 2001-2007)

TBI: traumatic brain injury; EC: external causes; NRS: neoplasias of the respiratory system; DM: diabetes mellitus; $C V D$ : cerebrovascular diseases; CLRD: chronic lower respiratory diseases ( $p$ value < 0.05 for EC, NRS, and CLRD). when compared to the other events. When evaluating each pathology group in each year of jurisdiction, it was noted that TBI had a low growth between 2001 and 2003 $(\mathrm{PRH}=3.9 / 10,000$, and 5.6/10,000 respectively), remained stable in the subsequent period, with an increase of only $0.7 \%$, but there was no statistically significant differences in these changes ( $\mathrm{p}$ value $=0.087$ ). However, when comparing the differences on the number of hospitalizations due to TBI and due to DM, CVD, and CLRD, it is noted that these pathologies had a higher incidence of hospitalizations, exceeding the TBI in 3-8 hospitalizations/10,000 inhabitants in 2001, but this difference almost disappeared in 2007.

Figure 3 shows that MRH for TBI remained in second place, just behind CVD. Also, the MRH for TBI was almost the double of the value of MRH for EC (CNM $=2.0 / 100,000$ inhabitants in 2001; $\mathrm{MRH}=3.4 / 100,000$ inhabitants in 2007), and seventeen times the MRH for CLRD $(\mathrm{MRH}=0.6 / 100,000$ inhabitants, in 2001; $\mathrm{MRH}=0.4 / 100,000$ inhabitants, in 2007). There was an increase in mortality of about $50.00 \%$ in the $\mathrm{MRH}$ for TBI in the period (4.5/100,000 inhabitants, in 2001; $6.7 / 100,000$ inhabitants, in 2007), but these variations were not statistically significant.

It is noted that TBI took the third place in LRH (about 12.0\%) in the period, just behind NRS and CVD. However, LRH for TBI was almost nine times higher than LRH for EC, and twenty times the value for CLRD. Although the growth of LRH for TBI has been slight between 2001 (11.4\%) and 2007 (12.2\%), this increase was statistically significant ( $\mathrm{p}$ value $<0.003$ ) as shown in Figure 4.

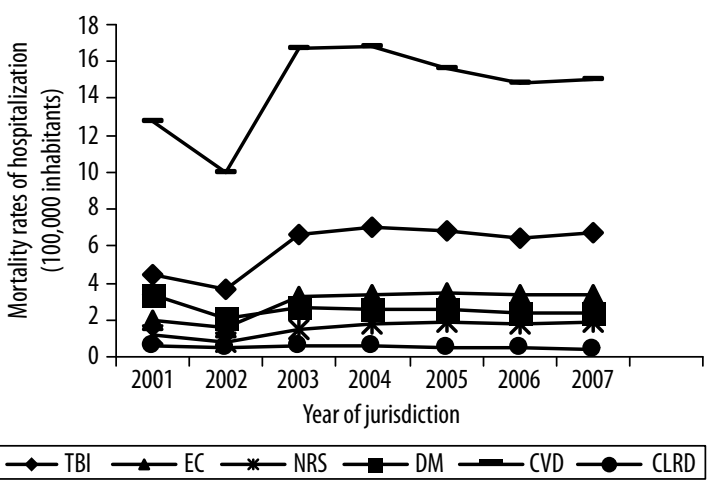

Figure 3 - Mortality rates of hospitalization on the public health system, for traumatic brain injury and other selected pathologies, according to the year of jurisdiction. (Brazil: 2001-2007)

TBI: traumatic brain injury; EC: external causes; NRS: neoplasias of the respiratory system; DM: diabetes mellitus; CVD: cerebrovascular diseases; CLRD: chronic lower respiratory diseases ( $p$ value $<0.05$ for EC, and NRS). 


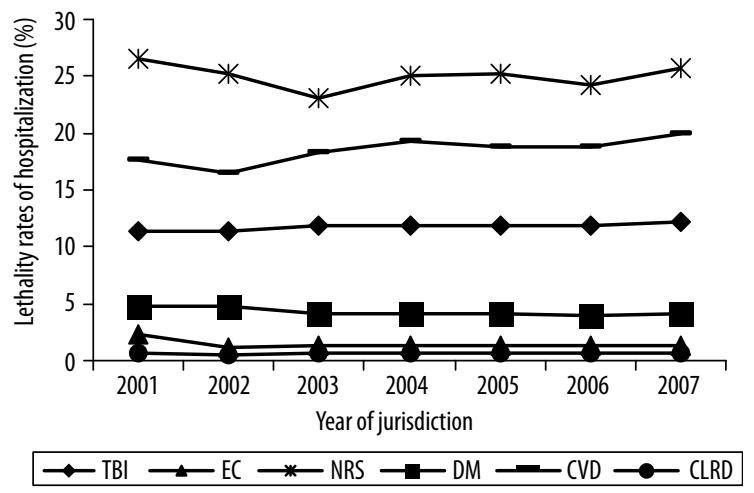

Figure 4 - Lethality rates of hospitalization on the public health system, for traumatic brain injury and the other selected pathologies, according to the year of jurisdiction. (Brazil: 2001-2007)

TBI: traumatic brain injury; EC: external causes; NRS: neoplasias of the respiratory system; DM: diabetes mellitus; CVD: cerebrovascular diseases; CLRD: chronic lower respiratory diseases ( $p$ value $<0.05$ for TBI, DM, and CVD).

\section{Discussion}

These findings clearly demonstrate that TBI in prevalent among men and young people, which was expected according to literature. Consistently, many studies point in this direction. ${ }^{5,8-10}$ The vulnerability to the occurrence of TBI in this group is due to sociocultural $^{15,16}$ and behavioral patterns that lead to more frequent exposure to accidents and aggressions. One example is the high consumption of alcohol which causes a decrease in attention and loss of sense of danger and, consequently, results in traumatic injuries such as TBI. ${ }^{17}$

The analysis of data of hospitalizations for TBI revealed that falls and traffic accidents were the most common circumstances of this pathology, followed by aggressions in a small proportion. A study using a similar populational database ${ }^{5}$ also found that falls were the leading cause of TBI. It was expected that most falls occur in the elderly population, as a consequence of aging. However, it was not observed. In a detailed analysis of the falls, not reported in this study, it was found that most occurred among the young patients. Therefore, age would not be the factor associated with this event. This can be explained by an incorrect encoding of falls in the HIS-NIS, i.e., individuals who have fallen from bikes, motorcycles or any moving vehicles, or even victims of aggression received the code of falls, when actually it was not, thus distorting the results.

Traffic accidents were the circumstances that have remained virtually unchanged throughout the period, which highlights the role of traffic safety measures such as seat belt use, more crosswalks for pedestrians, speed bumps, and other actions implemented after the promulgation of the Brazilian Traffic Code. Certainly, they help to reduce the severity and mortality of TBI, but they were not effective in reducing the number of hospitalizations. ${ }^{18}$ Possibly, the use of alcohol associated with vehicle driving ${ }^{12,17}$ and in particular the use of motorcycles has maintained TBI as a common event among trauma resulting from traffic accidents. In this study, the accidents involving motorcycles were the circumstance for TBI that led to the biggest increase in the number of hospitalizations, almost tripling between 2001 and 2007. This substantial growth has been observed on other analyses of traffic accidents in Brazi ${ }^{19}$ from early 2000. Part of that is due to the use of motorcycle as a means of formal and informal transportation.

Regarding the aggressions, which contributed in a smaller proportion for the number of hospitalizations for TBI, in most cases these circumstances have as an agent the firearms, which result in brain lesions of greater severity than the others ${ }^{20}$ and, consequently, lead to death at the site of the accident. As a consequence, aggressions contribute little to the estimates of nosocomial morbidity. ${ }^{21}$ Another aspect is the omission of the main source of injury at the admission, because sometimes the victim knows or lives with the offender and thus does not notify.22

When comparing the magnitude of hospital admissions in Brazil with other countries, like the United States $^{3}$ (84.9/100,000 inhabitants) and some European countries $^{4,11,23}$ ( 83.3 to $229 / 100,000$ inhabitants), it is observed that the national estimate is low, which could be explained by the existence of management problems and the difficulty to have immediate access to the services of mobile pre-hospital care for removal of victims from the accident site to the hospitals, along with inadequate units of trauma, ${ }^{24,25}$ especially the cases of TBI that require services and technology of high complexity, which increases the chance of dying at the accident site or in the emergency department without proper care.

It is also worth mentioning that the prevalence of TBI remained broadly stable from 2001 to 2007 , while some of the selected pathologies showed decrease. These findings suggest a lack of effective measures to reduce violence and accidents, although since 2001 these injuries has become part of the official agenda of the Ministry of Health in the National Policy for Reduction of Morbidity and Mortality from Accidents and Violence. ${ }^{26}$

The severity of hospitalizations for TBI may be evidenced by the estimates of mortality and lethality, which were higher than most of the other selected pathologies in this study. This is because of the importance of brain in human physiology, playing vital roles for maintenance of life. Consequently, lesions in this location usually are more severe when compared to other locations, which explains the higher morbidity and mortality rates when compared to other external causes. 
These findings should be viewed with some caution, because there is no uniformity in the selection of cases of TBI based on ICD-10 which complicates comparisons between the results of different studies. Furthermore, it is worth noting that the analysis included only patients hospitalized in services covered by the public health system; admissions in emergency rooms and patients who died at the scene or during removal to a health service were not accounted.

\section{Conclusion}

This study calls the attention to the necessity of directed efforts and public policies on the prevention of TBI. During the seven years of the National Policy for Reduction of Morbidity and Mortality from Accidents and Violence, a reduction in estimates of morbidity and mortality of TBI has not been reached, a fact that is supported by the results of this study. Concerning the deaths, which are completely preventable, they have occurred among young individuals in their most productive period. This certainly has a negative social and economic impact, for the loss of a loved one, and for the increase in expenses of the Social Security, because of temporal and definitive disabilities.

\section{Competing interests}

The authors declare that they have no competing interests.

\section{References}

1. Hyder AA, Wunderlich CA, Puvanachandra P, Gururaj G, Kobusingye OC. The impact of traumatic brain injuries: a global perspective. NeuroRehabilitation. 2007;22(5):341-53.

2. Polinder $\mathrm{S}$, Meerding WJ, van Baar ME, Toet $\mathrm{H}$, Mulder $\mathrm{S}$, van Beeck EF, et al. Cost estimation of injury-related hospital admissions in 10 European countries. J Trauma. 2005;59(6):1283-90.

3. Faul M, Xu L, Wald MM, Coronado VG. Traumatic brain injury in the United States: emergency department visits, hospitalizations and deaths 2002-2006. Atlanta (GA): Center for Disease Control and Prevention, National Center for Injury Prevention and Control; 2010.

4. Tennant A. Admission to hospital following head injury in England: incidence and socio-economic associations. BMC Public Health. 2005;5:21.

5. Koizumi MS, Lebrão ML, Mello-Jorge MH, Primerano V. Morbidity and mortality due to traumatic brain injury in São
Paulo City, Brazil, 1997. Arq Neuropsiquiatr. 2000;58(1):819.

6. Center for Disease Control and Prevention. Surveillance for traumatic brain injury-related deaths - United States, 1997-2007. MMWR. 2011;60(5):1-36.

7. Tagliaferri F, Compagnone C, Korsic M, Servadei F, Kraus J. A systematic review of brain injury epidemiology in Europe. Acta Neurochir (Wien). 2006;148(3):255-68.

8. Melo JR, Silva RA, Moreira ED Jr. Characteristics of patients with head injury at Salvador City (Bahia-Brazil). Arq Neuropsiquiatr. 2004;62(3A):711-4.

9. Myburgh JA, Cooper DJ, Finfer SR, Venkatesh B, Jones D, Higgins A, et al. Epidemiology and 12-month outcomes from traumatic brain injury in Australia and New Zealand. J Trauma. 2008;64(4):854-62.

10. Wu X, Hu J, Zhuo L, Fu C, Hui G, Wang Y, et al. Epidemiology of traumatic brain injury in eastern China, 2004: a prospective large case study. J Trauma. 2008;64(5):1313-9.

11. Koskinen S, Alaranta H. Traumatic brain injury in Finland 1991-2005: a nationwide register study of hospitalized and fatal TBI. Brain Inj. 2008;22(3):205-14.

12. Faria JW, Nishioka SA, Arbex GL, Alarcão GG, Freitas WB. Occurrence of severe and moderate traumatic brain injury in patients attended in a Brazilian Teaching Hospital: epidemiology and dosage of alcoholemy. Arq Neuropsiquiatr. 2008;66(1):69-73.

13. Instituto Brasileiro de Geografia e Estatística. (IBGE). Resultados do Universo do Censo 2000. Available at: > <http://www.ibge.gov.br/home/estatistica /populacao/ default>. Accessed on: Jan 5, 2009.

14. Datasus. Departamento de Informática do SUS. Sistema de Informação Hospitalar. Available at $<$ http://tabnet.datasus. gov.br/cgi/tabcgi.exe?sih/cnv/miuf.def>. Accessed on: Jan 7, 2009 and Fev 5, 2009.

15. Wagner AK, Sasser HC, Hammond FM, Wiercisiewski $\mathrm{D}$, Alexander J. Intentional traumatic brain injury: epidemiology, risk factors, and associations with injury severity and mortality. J Trauma. 2000;49(3):404-10.

16. Aryan HE, Jandial R, Bennett RL, Masri LS, Lavine SD, Levy ML. Gunshot wounds to the head: gang- and non-gangrelated injuries and outcomes. Brain Inj. 2005;19(7):505-10.

17. Tien HC, Tremblay LN, Rizoli SB, Gelberg J, Chughtai T, Tikuisis $\mathrm{P}$, et al. Association between alcohol and mortality in patients with severe traumatic head injury. Arch Surg. 2006;141(12):1185-91.

18. Farage L, Colares VS, Capp Neto M, Moraes MC, Barbosa MC, Branco JA Jr. Safety measures in traffic and hospital morbimortality in craniocerebral trauma in the Distrito Federal. Rev Assoc Med Bras. 2002;48(2):163-6.

19. Souza ER, Lima MLC. Panorama da violência urbana no Brasil e suas capitais. Cienc Saúde Coletiva. 2007;11(Supl):1211-22.

20. Solmaz I, Kural C, Temiz C, Seçer HI, Düz B, Gönül E, et al. Traumatic brain injury due to gunshot wounds: a single institution's experience with 442 consecutive patients. Turk Neurosurg. 2009;19(3):216-23.

21. Gawryszewski VP, Koizumi MS, Mello-Jorge MH. Morbidity and mortality from external causes in Brazil, 2000. Cad Saude Publica. 2004;20(4):995-1003.

22. Mesquita Filho M, Mello Jorge MHP. Características da morbidade por causas externas em serviço de urgência. Rev Bras Epidemiolol. 2007;10(4):679-91.

23. Andelic N, Sigurdardottir S, Brunborg C, Roe C. Incidence of hospital-treated traumatic brain injury in the Oslo population. Neuroepidemiology. 2008;30(2):120-8.

24. Colohan AR, Alves WM, Gross CR, Torner JC, Mehta VS, Tandon PN, et al. Head injury mortality in two centers with 
different emergency medical services and intensive care. J Neurosurg. 1989;71(2):202-7.

25. Mauritz W, Wilbacher I, Majdan M, Leitgeb J, Janciak I, Brazinova A, et al. Epidemiology, treatment and outcome of patients after severe traumatic brain injury in European regions with different economic status. Eur J Public Health. 2008;18(6):575-80.

26. Secretaria de Políticas de Saúde. Ministério da Saúde. Política nacional de redução da morbimortalidade por acidentes e violência. Rev Saúde Pública. 2000; 34(4):427-30.

\section{Correspondence address}

Raimundo Nonato Ribeiro Fernandes

Av. Sete de Setembro, 2284/1201

40080-001 - Salvador, BA, Brazil

Telefones: (71) 8816-3813/(71) 4009-8858

E-mail: raimundofernandes1@gmail.com 